City University of New York (CUNY) CUNY Academic Works

\title{
What it Means To Be Special: Two Sisters Discuss Their Experiences
}

Gene Fellner

CUNY College of Staten Island

Mark Comesanas

Fast Track Academy

Laritza Duperoy

Yaritza Duperoy

\section{How does access to this work benefit you? Let us know!}

More information about this work at: https://academicworks.cuny.edu/si_pubs/137

Discover additional works at: https://academicworks.cuny.edu

This work is made publicly available by the City University of New York (CUNY).

Contact: AcademicWorks@cuny.edu 
For published version see:

Gene Fellner, Mark Comesañas, Laritza Duperoy \& Yaritza Duperoy (2017)

What it means to be special: two sisters discuss their experiences, Disability \& Society, 32:3,

323-343, DOI: 10.1080/09687599.2017.1296817

To link to this article: https://doi.org/10.1080/09687599.2017.1296817

\title{
What it means to be special: two sisters discuss their experiences
}

\begin{abstract}
Pre-service Special Education teacher: What do you think of when you think of Special Ed?

Yaritza: You know a kid who needs extra help. I think of someone who doesn't understand, who isn't at the same level as everybody else. I see a kid who struggles more to comprehend what is being taught.
\end{abstract}

Laritza: I see a person pushed away, probably getting bullied, not really getting help.

\section{The study and its authors}

This case study examines what we can learn about the harms and benefits of special education classification from exploring the experiences of sixteen-yearold Laritza, a special education student, and her fifteen-year-old sister, Yaritza, who is in general education. Laritza and Yaritza came to the United States from Puerto Rico when they were 7- and 6-years-old respectively. They were placed in bilingual classes until the fifth grade when Laritza was classified as a student with a learning disability because she struggled to understand concepts her peers seemed to easily comprehend. In the ninth grade, Laritza was moved to general education for math but otherwise remained in self-contained special education classrooms. To the authors of this paper, Laritza's academic weaknesses do not seem severe and she could have easily thrived in an inclusive setting, possible with an aide to assist her. Her classification, however, aligns with research documenting that, in the US, "students of color as a group are disproportionately placed in more restrictive (meaning more segregated) special education placements than their White peers with the same labels" (Collins, Connor, and Ferri 2016, p. 5).

In fall 2014 and again in spring 2015, Laritza and Yaritza visited Author One's master's special education classes at the College of Staten Island (CSI) to tell their stories about how the labeling of one of them as special impacted their lives. Their narratives illuminated the burden that both sisters carry because of Laritza's classification. Laritza's narratives intertwine stigma, bullying and 
loneliness. For Yaritza, love and concern for Laritza coexist with envy for the attentions Laritza receives at home and her own need to feel special in the more commonly used sense of being unique and prized for one's own accomplishments. Their individual stories, building on and intermeshed with each other, created an overarching narrative about the effects of Laritza's special education classification on the two sisters.

The data on siblings of children diagnosed as "special" seem mostly gathered from small studies that lump together a broad range of severe disabilities. These studies generally do not give voice to the perspective of the individual with special needs; they present the perspectives of others (parents, siblings, medical professionals and school personnel). The vast majority of students with disabilities, however, are able, like Laritza, to represent themselves (The NCES fast facts tool 2015). This study contributes to existing research by giving voice to siblings one of whom is in special education and the other in general education. It is unusual in that the siblings dialog with each other about how their respective classification affects them.

We believe, furthermore, that our study supports and expands upon existing research in the field. Importantly, it privileges the perspectives of students and their inclusion in the research process. Laritza and Yaritza collaborated with Author One and Author Two on every aspect of this project. In this regard our study can be seen as belonging to the field of participatory educational research, a study conducted with students not on students (Knox, Mok, and Parmenter 2000; Stetsenko 2014).

Our study also highlights the role that institutionally imposed separation plays in facilitating a deficit framework through which the school community perceives students with special needs. Officially sanctioned segregation takes the form of exclusionary school ethos, classrooms separated by measured abilities, spatial isolation (location of classrooms), and labels that serve to reduce individuals to their deficits.

In this article, we first review the literature related to the benefits and harms of classifying students with special needs and their subsequent placement in exclusive or inclusive educational settings. We then review the methodologies we used to guide our study and our findings based on an analysis of videos taken during the classes at CSI and preparatory and debriefing meetings related to them. We conclude with a discussion and some final thoughts and recommendations.

\section{The benefits and harms of inclusive education: A brief review of the literature}

Research suggests that students labeled with disabilities perform better in inclusive settings (Nind and Wearmouth 2006; Dudley-Marling and Burns 2014) though successful inclusion relies on pedagogical strategies that foster academic success (Díez 2010; Honkasilta, Nind and Wearmouth 2006; Vehkakoski and 
Vehmas 2016). Maybe more important than any particular strategy are the attitudes informing educators' perspectives on students with special needs. School personnel often view these students through deficit lenses (Ho 2004; Dudley-Marling and Burns 2014), and the design and organization of school spaces often help produce and sustain narratives in which learning differences are interpreted as deficiencies (Goodfellow 2012). Demchuk (2000), refers to students in self-contained classrooms as being 'educated in exile' (95), their separation from other students harkening back to the days when those judged as abnormal were hidden away physically and metaphorically (Winzer 2007). Though students learn in many different ways and at many different rates, statistical evidence shows that students labeled with special needs in the United States are disproportionately poor, African American and Hispanic (Artiles et al. 2010; Harry and Klingner 2006). These statistics reveal the complicated intersections between race, class, disability and exclusion and challenge the pedagogical rationale for categorization, substituting for it an uglier narrative with roots in historic and institutionalized racism. Those labeled with special needs when young have poor graduation rates and job opportunities (Artiles et al. 2010; Díez 2010) when compared to their non-labeled peers, thus continuing the legacy of injustice towards poor people of color. On both pedagogical and ideological criteria, exclusion in education contests the democratic promise of quality education and opportunity for all.

Though physical isolation of students with special needs is the most visible manifestation of educational exclusion, conceptual biases that foster exclusion transcend physical enactments of segregation, affecting welfare of special needs students in inclusive settings as well. Indeed, the official categorization as 'special' is itself part of a practice that serves to predetermine the potential of a student in the minds of educators. Ho (2004) writes:

The child may no longer be regarded as an individual with unique abilities, learning styles, circumstances and aspirations. There is a popular assumption that having learning disabilities constitutes the whole identity of the student, and that every child with same diagnostic label is of the same kind and has the same instructional need. (88)

And

School officials and teachers who follow the law often still consider learning disabled students as less competent or inherently inferior (87).

The attitudes of educators, in turn, become part of a school culture and are easily adopted by general education students (Bunch and Valeo 2004) and, in the form of self-stigma, by those who are classified (Holley 2012; Bos et al. 2013). Though inclusive school environments appear to align with the ideals of democracy, in practice they often intensify a climate of exclusion characterized by bullying and loneliness that can lead students labeled as special to prefer exclusive settings. Díez $(2010,170)$ reports: 
The available data clearly indicates that peer behavior patterns have spurred exclusion in mainstream classrooms. ...At times extremely negative and even aggressive stigmatization raised its ugly head: parody, insult, aggravation and, occasionally, physical aggression that spilt outside the classroom and stained each and every school and extracurricular environment.

Differentiation strategies meant to serve all students within an inclusive environment are often "perceived as segregative" by those with special needs (Vlachou and Papananou 2015), highlighting the distance that still separates democratic ideals from the reality on the ground as well as the pedagogical challenges of educating students who learn in many different ways at many different rates and with varied strengths and weaknesses and distinct personalities. Whether in exclusive or inclusive settings, school environments often provide fertile ground for bullying and for feelings of shame, isolation, and reduced aspirations (Sabornie 1994; Hale 2015; Mishna 2003).

It is not surprising that institutional structures that foster exclusion and the attitudes that both generate and are generated by those structures mediate selfstigma and lower self-expectations among classified students who:

Adjust their expectations and aspirations according to their diagnosis and the fates of other people with the same diagnosis. (Ho 2004, 89)

Since 'self-concept and academic achievement' have been shown to be 'strong predictors of each other' (Dyson 2003, 2), it is essential to understand how school structures and educators' attitudes interactively function to produce climates in which students with disabilities are perceived and treated as "lesser" than their non-labeled peers.

Within climates that foster both conscious and unconscious practices that demean and exclude students with learning differences and disabilities, it is not surprising that students themselves, whether in general education or in special education, use the terms normal and special to identify themselves, a reflection of how the language of students reveal their internalization of the experience of schooling (Arneil 2009).

Structures that foster deficit views of students with special needs can be resisted. Indeed there are studies (Vlachou and Papananou 2015; Díez 2010; Honkasilta, Vehkakoski, and Vehmas 2016) that demonstrate how teachers with non-deficit views of disability and good practices can, at least within their classroom, make a significant difference in how students with special needs see themselves, and how students with and without special needs see each other.

\section{Background to study}

Author One's doctoral dissertation was based on his work with Author Two and his seventh grade classrooms in 2011, and Author Two and Author One 
continued working together once Author One became an assistant professor at the College of Staten Island (CSI). The following year, Yaritza was Author Two's student. A talented poet, she persuaded Authors One and Two to begin a weekly after-school poetry workshop. One day, Laritza came to the workshop. Author One had met her the previous year in her special education class when he was mentoring middle school teachers. At that time, Laritza barely spoke with him and he did not know she was Yaritza's older sister. She was quiet and often tuned out of classroom activities. Now, though shy, she was clearly engaged in the poetry session and seemed like a different person from the one Author One met a year earlier.

It was at the poetry workshop attended by Laritza that the idea for this study took root. Because of the dearth of research in which special education students and their siblings represent themselves, Author One suggested that Yaritza and Laritza could teach a class about Special Education to his preservice teachers (PSTs) at CSI and share their experiences of how they were affected by Laritza's classification; Author Two and Author One would facilitate. Author One believed teaching the classes together would be enlightening for the four of us and might further understanding about how the concepts of difference and deficits frame educational policy and affect student lives. Additionally, Author One wanted his PSTs to hear directly from students about the experience of being "special" or being a sibling of someone who was classified. He thought such a class would be more compelling than articles on the subject and would provoke critical reflection on Special Education and on his PST's own roles and responsibilities as future teachers.

Laritza, Yaritza and Author Two enthusiastically embraced Author One's proposal for which we received IRB approval and the written consent of both sisters and their mother. In the spring of 2014 we met in Author Two's office to prepare for teaching a class at CSI. We video recorded the prep sessions, the class that we taught together and the debriefing session following the class presentation. We repeated the process the following year with a different group of PSTs. By the end of the second year, we had nine hours of video documenting our work together.

This article is built around excerpts from what Yaritza and Laritza said at CSI and during our debriefing sessions.

\section{Methodology}

The field of Disability Studies in Education (DSE) frames the methodologies employed in this study. DSE emerged in the 1990s from the field of Disability Studies (DS) that arose a decade earlier to challenge the medical model of disability that dominates today (Baglieri et al. 2011). The medical model views disabilities as deficiencies located in the minds and bodies of individuals who are thus seen as "passive objects in need of treatment" (Vlachou and 
Papananou 2015, 74) who need to be 'normalized' or 'fixed.' DSE in contrast, understands disabilities as social constructs embedded in cultural practices rather than as individual defects. Altering social structures (including attitudes) can make individual differences less salient and debilitating. Though Laritza, as we shall see, is often ambivalent about inclusion, DSE strongly advocates for full inclusion holding that it is the educational environment, not a person alone, which produces disability. Because DSE recognizes the integrity of every individual as a valued member of society, it promotes research methods and practices that give voice to those who have been the subject of research in special education, and are the most affected by special education policy, but have nevertheless been denied self-representation within the field. In alignment with DSE, we chose participatory research and a narrative methodological approach for our study.

Participatory research 'has grown up around people who have historically lacked voice' (Nind 2011, 350), including students and even more so students with special needs. Research in which young people with disabilities and their siblings participate is crucial if we are to understand the perspectives of those most affected by educational policies on disability (Meltzer and Kramer 2016). In this project, Laritza and Yaritza, along with authors one and two, chose the excerpts from their talks that are included here as findings and helped identify and develop major themes for analysis and discussion. Though much of the language in this article was not easily accessible to them, we reviewed the article together, page by page, before submitting it for publication. To enhance the authenticity and credibility of our study, we strove to make certain that the text was understood and consented to by all of us.

For this study, we employed a narrative methodology (Smith and Sparkes 2008), which serves the goals of participatory research in that it seeks "to discover" how the subjects of the research "perceive reality" (19) through the stories that they tell. Through stories, readers can learn how those who have been historically marginalized perceive the effects on them of policies they had no role in designing. Simultaneously, while telling stories, participant-subjects can re-live their own experiences and begin, through reflection, to make sense of them (Gibson 2006). Bruner $(2004,693)$ explains, 'The culturally shaped cognitive and linguistic processes that guide the self-telling of life narratives achieve the power to structure perceptual experience, to organize memory, to segment and purpose-build the very "events of life."' Smith and Sparkes (2008, 19) write, 'If we change the stories we live by, we quite possibly transform and change our lives and society too.'

In our project, Laritza and Yaritza told stories about their experiences with each other and with peers in response to questions about disability and classification that were posed by Authors One and Two during our preparation and debriefing sessions and by PSTs at CSI. These stories, captured in the nine hours of video, became the data for this study. Author One transcribed the recordings and coded them for salient themes that were repeatedly invoked in Laritza's and Yaritza's tellings about their experiences. 
Author One's organization and analysis of the videos became the jump-off point for our collective discussions and (re)interpretations. Though his basic selections and categorizations remained intact throughout our discussions, Author Two, Yaritza and Laritza reviewed, interrogated and reframed them. In this way, we believe we have conducted authentic participant-research together (Tobin 2006) that has raised our collective understanding of disability and contributed to general knowledge about the subject.

\section{Major themes extracted from the video recordings}

Six themes, related to the production of stigma associated with being special and one related to siblings' experiences of disability repeatedly emerged in the stories told by Laritza and Yaritza:

Theme I: The need for extra help internalized as self-stigma.

Theme II: The production and institutionalization of stigma through physical and conceptual exclusion.

Theme III: The role of teachers' attitudes in perpetuating or preventing stigma.

Theme IV: Bullying

Theme V: The verbal language of stigma.

Theme VI: The burden of the sister who is not special.

In the findings below, excerpts from the stories are organized under their thematic category.

\section{Findings}

\section{Theme 1: The need for extra help internalized as self-stigma}

Y: From the beginning, we knew she needed help understanding stuff. My mom would sit down and try to figure out what she needed help with. Even in Puerto Rico it was slow for her, it wasn't just a difficulty of Spanish and English, it was all around subjects.

L: My mom said I had time-processing issues. I was slow; not slow, slow but I needed time to comprehend.

L: I had an aide; I had to have an aide. I needed help because I was special. 
L: My problem is when I have a question and I think it sounds dumb, and other people understand it already and the teacher says 'ok, write about this, ' I'll be like, 'Can you explain the question to me?'

Though there was consensus on Laritza's need for extra help in school, the special education structure through which that help was delivered, at least in hindsight, was problematic for both sisters; both voice ambivalence about its costs and benefits. Laritza often claimed it 'worked out well,' but she also viewed her abilities through a lens of deficiency that is mediated by her classification, her struggles in school, and her observations of how general education students are taught. Once when in fifth grade she visited a general education classroom and observed:

L: I noticed the teachers were different. I saw how they taught, and I thought, 'Why don't I get taught like that? That's hard. That's really hard. And then I went to my class and I was like, 'wow, we're totally different. I'm taking the easy road.' And from thereon, I started noticing.

The noticing reinforced the idea that:

\section{L: I'm really not that bright.}

There is no way to be certain that Laritza would not have internalized deficit views of herself or 'self-stigma' (Bos et al. 2013) had she not been defined as a student with special needs by school and family. Still, Yaritza and Laritza argue below that institutional (systemic) segregation facilitated stigma.

\section{Theme 2: The production and institutionalization of stigma through physical and conceptual exclusion}

It was in bilingual classes that both sisters first experienced stigma produced by spatial seclusion via self-contained classrooms (segregated on the basis of language) and geographic isolation (location in the school). Indeed Yaritza's experience in Bilingual Education may have given her insights into the role that exclusionary ideas and practices played in the development of stigma for Laritza within Special Education. The qualitative aspects of the segregated classrooms - their size and affordances - served to devalue students and was easy to interpret as officially sanctioned.

L: We (bilingual students) were in a small room.

L \& Y: (simultaneously) at the end of the hall,

L: Where nobody ever went.

Y: The room was a utility closet made into a classroom, so we had hooks and stuff all over the place; the teacher's desk could barely fit inside. It was very hard to maneuver, it was a very tiny room, and we were secluded all the way in the corner by the exit of the school. 
Y: Yeah. Special Ed, they were secluded too.

L: It was them and us in a corner. It felt like we were not part of the school.

Y: It feels like you're not important. They don't care enough to get valuable teachers, to give you a bigger class, to make sure you are really learning stuff. We're trying to pick up another language and to learn all these techniques in writing, math and science and we only have one little teacher and one little classroom and we were secluded. If they would have paid more attention it would have helped us immensely.

The humiliation or 'symbolic violence' (Bourdieu and Wacquant 1992) of being marginalized geographically - literally located at the margins of the school (by the exit, almost outside, 'where nobody ever went'), in a 'tiny' classroom where even the teacher becomes 'tiny' in the students' minds broadcasts to the school community that these students do not matter. Such geographical isolation is central to the creation of stigma and arguably serves to facilitate an ethos of bullying (a subject we address below).

For Laritza and Yaritza, geographic isolation went hand-in-hand with conceptual isolation:

Y: The classes that were Special Ed, they were pushed aside and ignored.

L: Not ignored,

Y: Yeah, ignored.

L: Hmmm.

Y: Because when I was on the yearbook committee they'd forget about Special Ed students.

L: Yeah, that.

Y: They were the last to come to mind. Like l'd be the one [to say] 'what about the Special Ed kids?' Because you didn't really hear about them or anything.

Institutional practices that separate students geographically based on a disability designation, a form of social exclusion (Morris 2001), broadcasts that these students are "special" and reinforces deficit attitudes toward disability among students and teachers.

\section{Theme 3: The role of teachers' attitudes in perpetuating or preventing stigma}

Laritza describes her dehumanizing experience with a teacher who, because of her own deficit views towards disability, identified Laritza as a category rather 
than as an individual thus perpetuating the identification of being special with deficiency.

L: My art teacher, my freshman year, she's like, 'So you guys are all in the same class?' And I say,

'No, I go to Special Ed.

And she's like, 'Oh, you do?'

'Yeah'

She's like, 'You don't look like it.'

'What am I supposed to look like?'

She's like, 'Oh no, you just seem like not, you know, needing help.'

I'm like, 'What do you mean?'

'Oh, because you guys usually act a certain way, not really respecting or behaving.'

After that year, I never had her again. Whenever I see her in the hallway she's like, 'Hi.'

I'm like, 'Hi, bye' (dismissive gesture).

During our debriefing session, Yaritza pointed out that Laritza's awareness and anger at how others stereotype her has not prevented her from adopting a stereotyped and diminished view of herself. When Laritza repeats:

L: I still think I'm not smart.

Yaritza prods:

Y: Smart enough to go to college?

L: Yeah.

Y: From where does that idea come from? From being in Special Ed!

L: Yeah.

Y: You take being in Special Education to the heart. All those years you embraced it; now you think you're stupid, that you can't go to college, that you're weird. That you don't know anything because you're Special Ed.

L: Well, yeah. But I don't like, 'Oh yeah, so this is what I am.' I try my best to change and not be what they mark me, what they label me as. I can prove them wrong.

When Author Two asks her how she can 'prove them wrong,' Laritza tells the story of surprising a teacher by correctly answering a question the teacher was certain she could not answer. By doing so, Laritza proved she was smarter than the teacher thought she was, which is to say not as special. 
At this point Author Two explains how a teacher's perception of special education classification can confine a student within a framework that takes deficiency as the student's defining condition.

A2: In your example, the teacher asks a question, and she goes to you but didn't expect you to get it right. You get it right. She's like, 'Oh wow.' That helps boost you to say, 'I just proved her wrong.' That could have gone another way. You could have been wrong, then her reaction would have been, 'Yeah, that's why I didn't want to pick her in the first place.' And it could have forced you in the opposite direction. Like, 'Maybe I am dumb.' When the truth is that Yaritza gets questions wrong all the time too, but hanging in the balance of one answer isn't all of that for her. If she gets a question wrong it's like, 'Whatever.' But for you, hanging in the balance of one question is your confidence as a person who says, 'Yes I can do this.' Every question counts for you more than it counts for someone who's not thinking about that. [L nods]

A1: Because Yaritza doesn't have that category hanging over her.

A2: She doesn't. And if Yaritza gets something wrong teachers will just say, 'Well she made a mistake,' whereas in Laritza's case the teacher thinks, 'She's not smart.' And that's not true. I think there's a whole bunch of layers. We're talking about one layer, which is that there's this label you internalize. Another layer is the confidence issue, and still another layer is at what point do you need help and when do you not really need help - it just requires a little more hard work. Then at what point does it have to do with the type of help you're getting and how you feel about that help - which is affected by this other layer, which is that you just don't have the confidence. There are a whole bunch of layers. And it's hard to separate.

\section{L: It's like an onion.}

The stories told by Laritza and Yaritza also included one instance of a teacher who challenged the deficit lens that the structural policies and classifications impose, pointing to the importance of perceptive and caring teachers to disrupt the deterministic force of exclusionary policies. It was due to this teacher's recognition of Laritza's potential and her advocacy that Laritza is now taking a general education mathematics class. Laritza is proud of her achievement:

L: In $8^{\text {th }}$ grade I was given a choice of being in normal ed math, still in Language Arts Special Ed. With that as an accomplishment, instead of going to a bad school I went to one of the magnet schools, one of the top ones.

Teachers, being in positions of power, not only have a great effect on how students feel about themselves, they also model permissible attitudes and can advance or obstruct a student's possibilities for academic success. Their 
pedagogical practices, when reflecting deficit attitudes toward disability, mediated by institutional policies fostering marginalization of students with disabilities, arguably creates an environment in which bullying can thrive.

\section{Theme 4: Bullying}

One of the most depressing partners of special education is bullying, which was mentioned repeatedly in the classes at CSI as it is in the literature on special education (Hartley et al. 2015; Mishna 2003). It is unsurprising that a combination of official categorization, bullying and humiliating treatment by others mediates feelings of inferiority and fear. Students who are bullied often respond to these feelings through "avoidance strategies" (Bellmore, Chen, and Rischall 2013; Garnett et al. 2015) or "distancing" (Hartley et al. 2015). Laritza uses a number of strategies to avoid being bullied. For example, she socializes almost exclusively with other students labeled with disabilities or stays by herself:

L: At lunchtime we usually sit with our own type, you know normal people [gesturing to one side], us (gesturing to the other side]. We used to go in the corner and not get bothered by anybody. Basically because of bullying. Because of that, we stayed with our own people.

Y: Because of bullying, her whole confidence was brought down. They were secluded, they were made fun of, you guys are stupid; it still affects her. She'd rather be alone than with other people because she's afraid of how they'll think of her and that's from the bullying. She loves to draw, she's an amazing artist but she never joined an art club, she rarely shows her art to her friends. Bullying impacted her from the beginning; as soon as they started it brought her confidence down and kept it down.

Another avoidance strategy that Laritza uses is to not participate in classes that include "normal" students so as to not draw attention to herself:

L: Having class with the normal ed people, that scared us. By us I mean me and my friends. We're afraid to ask questions because we think they'll notice we're special ed. So we just stay shut.

Sometimes, however, Laritza employs retaliatory responses (Bellmore et. al, 2013) in the form of talking back to the bully:

L: For me, being in Special Ed was always about bullying. You don't know this, you're dumb. Like, 'We don't want to be with her.' If I was put into a normal people group, they would look at me like I had six heads, like what are you doing here? In Special Ed, it was be bullied or fight back. I became tough. And I forgot to tone it down at home; l'd talk back to my mom and dad. It affected a lot of issues at home. It reaches a point 
where you can't take it no more [almost in tears]. That's why people do what they do. Well not people, but kids who get too pushed to the limit.

In Laritza's mind, being labeled as "special" was inseparable from being bullied, and her experience with being bullied mediated her willingness to socialize with students considered "normal" and her attitudes towards friends and family. The ethos of marginalization in schools that arguably created a permissive environment for bullying was infused with language that demeaned those with disabilities. We turn to this theme below.

\section{Theme 5: The verbal language of stigma}

L: I have gym with normal people. By normal people I mean normal ed. From there we go to math. Math is all Special Ed. Next period we have whatever, like normal people. Only in the classes we need do we have our people.

The literature cites examples of special education students describing their status as not normal, but often the language they use is not explicitly noted or analyzed. As may now be obvious, Yaritza and Laritza repeatedly oppose being 'special' to being 'normal.' During the classes at CSI, they did so 29 times. They never used the official term 'general education' in opposition to 'Special Ed' because it does not do justice to the lived meaning of Special Education as abnormal, unhealthy and inferior. When Laritza did not identify herself as 'special,' she used the terms 'weird' (three times), 'our people' (twice), and 'us people' (once). In many ways, Laritza and Yaritza embody the language of deficiency to describe Special Education. By doing so they have absorbed the still hegemonic medical model of disability that sees disability as ... directly caused by the person's mental or physical impairments' (Ho 2004, 3).

We have listed some examples of the uses of the term 'special' during our discussions.

1. Special $=$ different

L: I see myself as weird, and by weird I mean, 'I'm not like you.'

L: If I was put into a normal people group, they would look at me like I had six heads.

2. Special $=$ needing help because of a cognitive obstacle

L: He's even more special than me (referring to an adult who can't write his name).

3. Special = unhealthy and inferior

L: They, the normal people, had nothing wrong with them [i.e. to be special is to have something wrong with you].

4. Special $=$ victimized 
L: They, the normal people, never got bullied.

Y: They knew the language.

Y. They weren't labeled.

L: We were labeled.

Y: The bilingual kids.

L: The special ed kids.

Y: The ones who don't understand.

To be special is to be different, needy, sick, inferior and vulnerable. These definitions are embedded in the extemporaneous language of students regardless of their classification. That special has become a pejorative term in many schools serves as a critique of official education policies.

\section{Theme 5: The burden of the sister who is not 'special'}

Y: I was envious of the amount of attention my mother gave to her. She got more attention, she got more rewards for grades that I got all the time. It was just more special for her. She got more things and she got more praise.

L: I mean I didn't see it as jealousy or envy or whatever you were feeling. I seen it as like 'she's special,' like pity, as if I was S-P-E-C-I-A-L [stage whispering now]. That's how I looked at it. That's how I felt. Mom is sending you because she thinks I can't do it alone. But then at the same time I couldn't do it alone.

Studies on siblings of individuals with special needs provide evidence that a broad range of emotions, from love and empathy to resentment and anger color the relationship (Solomon 2012; Kao et al. 2011). The range of emotions is probably similar to that which circulates between un-classified siblings, but the official labeling of one sister as special can seem to sanction giving more attention to the special sibling.

This study suggests that even when the child with special needs is able to represent herself, reflectively think about abstract concepts (as judged by Laritza's full engagement with this research project), and independently take care of her day-to-day needs, the sibling in general education may still struggle with some of the emotional burdens that weigh on youth whose siblings are unable to function independently. We have seen above how Yaritza advocates for Laritza, but she often feels overshadowed by her as well.

Y: Since pretty much the beginning, I would see that my mom would try to help her more. I would understand what they were teaching her - she was one grade above me - I was in fourth, she was in fifth. It's always 
been like that. Whatever they were teaching her, I would understand. I would help her. When it came to grades, I would come out with Bs and As and the lowest a $C$ and it would be like 'try harder.' Laritza came out with Cs and Ds and it's like, 'YAY, you're trying. You're doing great.' I'm sitting back and trying my hardest and you never saw my mom come up to me and ask me if I had trouble with homework. So it was definitely different in the way she treated us. If I was mad about helping her she was like, 'Laritza needs help. You have to help her, she's your big sister.' But never did she do it for me.

Laritza understood that her being special was a burden for Yaritza but felt powerless to change the dynamic:

L: But you didn't see it as I saw it. I mean I had to get help. You had no other choice but helping me, but for me it was a good thing. It made me feel good about myself. It gave me more motivation.

The same dynamic might exist between them even if Laritza were not officially classified. Still, the official labeling of Laritza as 'special' mediates how they think of themselves and each other. Yaritza's resentment is partially fueled by her belief that Laritza is not as special as she seems, and that Laritza seeks more help than she actually needs. Laritza's successful move to general ed mathematics might support that contention. At the same time, Yaritza, who is special in her own right but according to the more common connotation of the term, does not get recognition for her achievements. Yaritza is Laritza's chief advocate, but also feels that 'I live, a little bit, in her shadow.'

\section{Discussion}

In this article, we have used Laritza's and Yaritza's stories about their own experiences to broaden the lens through which we understand the consequences of being classified as a student with special needs. We do not claim that their experiences represent those of other siblings one of whom is classified. As Ho $(2004,89)$ emphasizes, 'students diagnosed with learning disabilities have vastly different experiences, depending on the environment and availability of accommodations.' The literature provides evidence, however, that the experience of Special Education that Laritza and Yaritza describe is not unique, and we believe our interrogation of their experiences adds to and deepens the body of knowledge that already exists about special education classification.

We also believe that the narrative and participatory methodologies that guided our research provided both Laritza and Yartiza with the opportunity to reflect upon how the categorization of one of them as 'special' has affected their trajectories in school and their relationship with each other. We cannot overstress the importance of providing a safe forum for students and educators to seriously listen to each other's stories.

Through those stories all participants can consider how school structures mediate sense of self and possibilities and work together to make those 
structures more supportive of all students. During the dialogs between Laritza and Yaritza about their relationship with each other (L: 'I didn't see it as jealousy or envy or whatever you were feeling;' Y: 'You didn't see it as I saw it'); when Laritza is considering with us her ability to transcend the constraints of her classification (Y: 'All those years you took [being in special education] it to the heart; now you think you're stupid.']; or when making sense of the multilayered conditions that mediate her performance in school, (L: 'It's like an onion'], we were all aware that Yaritza and maybe Laritza especially were beginning, in dialog with authors one and two, to reinterpret their experiences with special education and through that reinterpretation rewrite their own possibilities (L: 'I could prove them wrong'). In this way our study acknowledges the important role, within participatory research, that teachers can have in helping students to know themselves better provided they listen carefully to them, "re-presenting" what they receive from their students "not as a lecture, but as a problem" (Freire 1993, 90).

Certainly, the issues we address in this article find echo in the research on disability. These include the correlation between being in special education and both the production of stigma and the experience of being bullied; the important role that educators and school structures can play in both the perpetuation and prevention of practices that foster exclusion; and the burden of being a sibling who is 'not special.'

Labeling and designated special education classes further the stigmatization of students with disabilities just as historically 'special schooling' marginalized 'those it purported to help' (Winzer 2007, 25). However, Ho (2004) lists many important reasons to diagnose the learning disabilities of students in special education, and Hibel $(2010,313)$ writes, 'The benefits of participating in a specialized educational program may far outweigh....potential educational and psychological costs.' For students like Laritza, however, the reverse may be closer to the truth. We would like to see a world in which being special incurs no cost at all. During our numerous sessions together, Laritza did not feel like an outsider or like someone disabled. Her voice counted as much as the voices of everyone else. She joined us in unraveling the meanings of her experiences, and proved capable in thinking abstractly and understanding complicated concepts. The girl who first came to our poetry workshop and who was described by both herself and Yaritza as keeping to herself was outgoing, outspoken and thoughtful. Her full engagement with our research made us all question the process through which she was placed in the most exclusionary schoolroom setting (a self-contained classroom) rather than in an inclusive one with appropriate modifications and/or accommodations as needed, and suggested to us that the school officials who classified her perceived her through a triple deficit lens in which her apparent slowness in processing information, her race and her lack of English fluency were all seen as mutually enforcing deficiencies that demanded exclusion. Though it has not been the focus of our article, we believe that the theoretical framework of scholars who join Disability Studies with Critical 
Race Theory (DisCrit) (Subini, Connor, and Ferri 2013) in order to make visible the interdependence between perceptions of race, disability and English language fluency and serve to explain the disproportion of youth of color and English Language Learners who are classified with disabilities (for example see Artiles et al. 2010) can help us understand why Laritza was placed in a selfcontained setting. In the United States, multiple oppressions, with deep historical and cultural roots, combine to misdiagnose, segregate and obstruct students from reaching their full potential.

Despite our belief in inclusive education, we want to acknowledge Andrew Solomon's insight in Far from the tree (2012) that though diversity is crucial to education and life, we also all need to be and learn with people who experience the world as we do. Solomon (2012) proposes two types of identities, vertical and horizontal. Vertical identity represents those characteristics and dispositions that are passed down from parents to children and facilitate their recognizing themselves in each other. Children who are 'special' and their parents, however, often find it difficult to recognize themselves in each other because they do not share important characteristics. Deaf children, for example, usually have hearing parents. In such families, children experience the world in ways radically different from their parents, and they may seek people who share their experience of disability, or what Solomon calls 'horizontal identities' in order to affirm their identities and succeed academically. Graduates from schools for the deaf, for example, have a much greater statistical chance of academic success than those in 'inclusive settings.' For at least some 'specialties' then, nurturing horizontal identities appears to be an important facilitator of academic and social achievement and of self-fulfillment. As we debriefed, Author One explained the concept of horizontal identities. Laritza excitedly interrupted him, "that's me" to emphasize her recognition of self in the description. She continued:

\section{L: I feel safer when I'm in my own class with my own type of people. It's} more like a home.

\section{Even if the label were pulled off, I would still be special.}

We have argued that the official labeling of Laritza as special mediated deficit perspectives and practices on the part of educators and students, which, in turn, aggravated her sense of difference and inferiority. Though the four of us agree that Laritza identifies as special at least in part because she was identified as special, and that children (like the rest of us) do not fully know themselves (Gallacher and Gallagher 2008), and cannot know themselves by themselves, we still need to respect and consider Laritza's analysis of her own experiences. Her stance on being "special" highlights inherent contradictions in the vision and meaning of inclusion (Norwich 2002). It poses the challenge of serving each child without producing stigma while also serving children, together, in alignment with democratic ideals and the demonstrated value of learning both through and with differences. It reaffirms the need for analytical, caring and continuous reflective 
dialog, untarnished by deficit frameworks, between students, parents and educators, in order to serve the needs of students.

\section{Final thoughts and recommendations}

Author Two is now the principal of Uplift Academy in Newark, NJ that serves overage and undercredited students. About $30 \%$ of these students are classified with special needs but there are no self-contained classes, 'nobody knows who has what,' and needs are not accepted as deterministic of a student's potential since social context is understood to be a mediator of both perception and performance. Difference exists of course, but it is not the defining lens through which students are judged, and labels that broadcast weaknesses do not publically brand students. By making this point, we are not arguing that there is never a time for grouping students together on the basis of specialties, talents or abilities nor are we arguing that all specialties be thought of in the same way or that there is only one way to serve all students. We are arguing that no system should create, through structural policies, the ideas of 'normal' and 'special.' We need, as Klaus Wedell $(2008,128)$ argues, 'a system which starts from the recognition of diversity' rather than one in which difference is conceived as an 'add-on' that needs to be accommodated.

Laritza and Yaritza formed some of these ideas in their own words:

Y: If you're special in one thing, they put you in Special Ed.

L: Don't make it so obvious that they need special help.

Y: Call it [Special Ed] something different.

Y: I understand you might have an aide, but it's just the way people interpret it.

L: Basically it's about how people treat you, how adults treat you.

Y: If you could know them as a person, why know them just as a grade?

L: They're knowing you as a piece of paper

We would like to make some recommendations based on our study.

Research:

More research is needed that explores:

1. The verbal manifestations of stigma in relationship to disabilities. Does this language mirror the culture of the school towards disability and does it change as school policies change? Is the language of stigma in regards to disability pervasive across different demographic criteria? 
2. How horizontal identities mediate educational achievement, emotional well-being, and the very concept of difference within contexts that celebrate diversity and welcome learning differences.

3. The potential of participant narrative research to stimulate reflexive awareness of the relationship between special needs classification and sense of self.

4. Models of inclusion, even if still only theoretical, which successfully address each child's different learning needs without producing stigma and while still celebrating communities of diversity in which we all learn from each other.

5. The complicated intertwining of race, class, gender and disability in the determination of disability.

Practice:

We believe that our study suggests that the following practices may significantly improve the lives of special education students.

1. Raise awareness among educators of the ways in which official disability categorizations and the stigmatizing language that surrounds disability can mediate, on an unconscious level, negative biases and perceptions about disability. Awareness of these dynamics makes possible the dismantling of attitudes and structures that foster exclusion and stigmatize difference.

2. Discontinue exclusionary practices, such as geographic marginalization within schools and the public labeling of students. Explore, as Norwich (2002) suggests, making Individual Education Plans for all students so that every student feels special.

3. Provide educators with the time, the resources, and the professional development needed to develop trusting relationships with students in which all voices are respected and in which special needs can be honestly and non-judgmentally discussed and reflected upon by all stakeholders.

4. Recognize that some siblings of students with special needs may also be burdened by their sibling's disability categorization. These students also need the services noted in point 3 above.

5. Avoid ideological rigidity. The complex construction of disability that often combines multiple oppressions of race, class, birth language and special needs; the tensions between serving the needs of every child while 
affirming and practicing inclusion; the knowledge that "practices of differentiation, even if supportive, may be perceived to be segregative" (Vlachou and Papananou 2015, p. 84), and the multiple and often selfcontradictory perceptions that surround disability make dubious any claim of certainty of how best to deal with any particular special needs student in any particular context.

Finally, though we are heartened by the trend toward inclusive education, it is difficult to seriously address inclusion or the issues of special needs until we address the inclusiveness and exclusiveness of our communities and the very concept of what it means to be normal.

\section{References}

Annamma, Subini Ancy, David Connor, and Beth Ferri. 2013. "Dis/Ability Critical Race Studies (DisCrit): Theorizing at the Instersctions of Race and Dis/Ability." Race Ethnicity and Education 16 (1): 1-31. https://doi.org/10.1080/13613324.2012.730511.

Arneil, Barbara. 2009. "Disability, Self-Image, and Modern Political Theory." Political Theory 37 (2): 218-42.

Artiles, Alfredo J., Elizabeth B. Kozleski, Stanley C. Trent, David Osher, and Alba Ortiz. 2010. "Justifying and Explaining Disproportionality, 1968-2008: A Critique of Underlying Views of Culture." Exceptional Children 76 (3): 279-99.

Baglieri, Susan, Jan W. Valle, David J. Connor, and Deborah J. Gallagher. 2011. "Disability Studies in Education: The Need for a Plurality of Perspectives on Disability." Remedial and Special Education 32 (4): 267-78. https://doi.org/10.1177/0741932510362200.

Bellmore, Amy, Wei-Ting Chen, and Emily Rischall. 2013. "The Reasons behind Early Adolescents' Responses to Peer Victimization." J Youth Adolescence 42: 275-84. https://doi.org/10.1007/s10964-012-9825-0.

Bos, Arjan E. R., John B. Pryor, Glenn D. Reeder, and Sarah E. Stutterheim. 2013. "Stigma: Advances in Theory and Research." Basic And Applied Social Pscyhology 35: 1-9. https://doi.org/10.1080/01973533.2012.746147.

Bourdieu, Pierre, and Loíc J. D. Wacquant. 1992. An Invitation to Reflexive Sociology. Chicago, IL: University of Chicago Press.

Bruner, Jerome. 2004. "Life as Narrative." Social Research 71 (3): 691-710.

Bunch, G, and A. Valeo. 2004. "Student Attitudes toward Peers with Disabilities in Inclusive and Special Education Schools." Disability \& Society 19 (1): 61-76. https://doi.org/10.1080/0968759032000155640.

Collins, Kathleen M., David J. Connor, and Beth A. Ferri. 2016. "Dangerous Assumptions and Unspoken Limitations: A Disability Studies in Education Respons to Morgan, Farkas, Hillemeier, Mattixon, Maczuga, Li, and Cook (2015)." Multiple Voices for Ethnically Diverse Exceptional Learners 16 (1): 416. 
Demchuk, Laura. 2000. “Children's Perceptions and Attitudes about Special Educaiton." Doctoral dissertation, Toronto: University of Toronto, Ontario Institute for Studies in Education.

Díez, Anabel Moriña. 2010. "School Memories of Young People with Disabilities: An Analysis of Barriers and Aids to Inclusion.” Disability \& Society 25 (2): 163-75. https://doi.org/10.1080/09687590903534346.

Dudley-Marling, Curt, and Mary Bridget Burns. 2014. "Two Perspectives on Inclusion in the United States." Global Education Review 1 (1): 14-31.

Dyson, Lily L. 2003. "Children with Learning Disabilities within the Family Context: A Comparisonwith Siblings in Global Self-Concept, Academic Self-Perception, and Social Competence." Learning Disabilities 18 (1): 1-9.

Fellner, Gene, Mark Comesañas, Laritza Duperoy, and Yaritza Duperoy. 2017. "What It Means to Be Special: Two Sisters Discuss Their Experiences." Disability \& Society 32 (3): 323-43. https://doi.org/10.1080/09687599.2017.1296817.

Freire, Paulo. 1970. Pedagogy of the Oppressed. New York: Continuum.

Gallacher, Lesely-Anne, and Michael Gallagher. 2008. "Methodological Immaturity in Childhood Research? Thinking through 'Participatory Methods."' Childhood 15 (4): 499-516.

Garnett, Bernice R., Katherine Masyn, Bryn Austin, David Williams, and Kasisomayajula Viswanath. 2015. "Coping Styles of Adolescents Experiencing Multiple Forms of Discrimination and Bullying: Evidence from a Sample of Ethnically Diverse Urban Youth.” Journal of School Health 85 (2): 109-17.

Gibson, Suanne. 2006. "Beyond a 'Culture of Silence': Inclusive Education and the Liberation of "Voice."' Disability \& Society 21 (4): 315-29.

Goodfellow, Athena. 2012. "Looking through the Learning Disability Lens: Inclusive Education and the Learning Disability Embodiment." Children's Geographies 10 (1): 67-81.

Hale, Christopher. 2015. "Urban Special Education Policy and the Lived Experience of Stigma in a High School Science Classroom." Cultural Studies of Science Education 10 (4): 1071-88.

Harry, Beth, and Janette Klingner. 2006. Minority Students in Special Education? Understanding Race \& Disability in Schools. New York: Teachers College Press.

Hartley, Michael T., Sheri Bauman, Charisee L. Nixon, and Stan Davis. 2015. "Comparative Study of Bullying Victimization among Students in General and Special Education.” Exceptional Children 81 (2): 176-93. https://doi.org/10.1177/0014402914551741.

Ho, Anita. 2004. "To Be Labelled, or Not Labelled: That Is the Question.” British Journal of Learning Disabilities 32: 86-92.

Holley, Lynn C. 2012. "Reconceptualzing Stigma: Toward a Critical Anti-Oppression Paradigm." Stigma Research and Action 2 (2): 51-61. https://doi.org/0.5463/SRA.v1i1.9.

Honkasilta, Juho, Tanja Vehkakoski, and Simo Vehmas. 2016. "The Teacher Almost Made Me Cry' Narrative Analysis of Teachers' Reactive Classroom Management Strategies as Reported by Students Diagnosed with ADHD." Teaching and Teacher Education 55: 100-109. 
Kao, B., L Romero-Bosch, W Plante, and D Lobato. 2011. "The Experiences of Latino Siblings of Children with Developmental Disabilities." Chid: Care, Health and Development 38 (4): 545-52.

Knox, Marie, Magdalena Mok, and Trevor R. Parmenter. 2000. "Working with the Experts: Collaborative Research with People with an Intellectual Disability." Disability \& Society 15 (1): 49-61. https://doi.org/10.1080/09687590025766.

Meltzer, Ariella, and John Kramer. 2016. "Siblinghood through Disability Studies Perspectives: Diversifying Discourse and Knowledge about Siblings with and without Disabilities." Disability \& Society 31 (1): 17-32. https://doi.org/10.1080/09687599.2015.1127212.

Mishna, Faye. 2003. "Learning Disabilities and Bulllying: Double Jeopardy." Journal of Learning Disabilities 36 (4): 336-47.

Morris, Jenny. 2001. "Impairment and Disability: Constructing an Ethics of Care That Promotes Human Rights.” Hypatia 16 (4): 1-16.

Nind, Melanie. 2011. "Participatory Data Analysis: A Step Too Far?" Qualitative Research 11 (4): 349-63. https://doi.org/10.1177/1468794111404310.

Nind, Melanie, and Janice Wearmouth. 2006. "Including Children with Special Educational Needs in Mainstream Classrooms: Implications for Pedagogy from a Systematic Review." Journal of Research in Speical Educational Needs 6 (3): 116-24. https://doi.org/10.1111/J.1471-3802.2006.00069.x.

Norwich, Brahm. 2002. "Education, Inclusion and Individual Differences: Recognising and Resolving Dilemmas." British Journal of Educational Studies 50 (4): 482502.

Sabornie, Edward. 1994. "Social-Affective Characteristics in Early Adolescents Identified as Learning Disabled and Nondisabled." Learning Disability Quarterly 17 (4): 268-79.

Smith, Brett, and Andrew C. Sparkes. 2008. "Narrative and Its Potential Contribution to Disability Studies." Disability \& Society 23 (1): 17-28. https://doi.org/10.1080/09687590701725542.

Solomon, Andrew. 2012. Far from the Tree. New York: Scribner.

Stetsenko, Anna. 2014. "Transformative Activist Stance for Education." In Psychology in Education, edited by Tim Corcoran, 181-98. The Netherlands: Sense Publishers.

"The NCES Fast Facts Tool Provides Quick Answers to Many Education Questions (National Center for Education Statistics).” n.d. Accessed August 8, 2015. https://nces.ed.gov/fastfacts/display.asp?id=64.

Tobin, Kenneth. 2006. "Qualitative Research in Classrooms: Pushing the Boundaries of Theory and Methodology." In Doing Educational Research, edited by Kenneth Tobin and Joe Kincehloe, 15-57. Rotterdam, The Netherlands: Sense Publishers.

Vlachou, Anastasia, and Ioanna Papananou. 2015. "Disabled Students' Narratives about Their Schooling Experiences.” Disability \& Society 30 (1): 73-86. https://doi.org/10.1080/09687599.2014.982787.

Wedell, Klaus. 2008. "Confusion about Inclusion: Patching up or System Change?" British Journal of Special Education 35 (3): 127-35. https://doi.org/0.1111/j.1467-8578.2008.00386.x. 
Winzer, Margret A. 2007. "Confronting Difference: An Excursion through the History of Special Education." In The SAGE Handbook of Special Education, 22-35.

London: SAGE Publications. 